\title{
Effects of Exogenous Spermidine on Carbon and Nitrogen Metabolism in Tomato Seedlings under High Temperature
}

\author{
Xi Shan, Heng Zhou, Ting Sang, Sheng Shu, Jin Sun, and Shirong Guo ${ }^{1}$ \\ Key Laboratory of Southern Vegetables Crop Genetic Improvement of Ministry of Agriculture, \\ College of Horticulture, Nanjing Agricultural University, Nanjing 210095, People's Republic of \\ China
}

\begin{abstract}
AdDitional INDEX wORDs. high-temperature stress, exogenous substance, enzyme activity
Abstract. We investigated the effects of exogenous spermidine (Spd) on the carbohydrate, nitrogen (N), and endogenous polyamine status of tomato (Solanum lycopersicum) seedlings exposed to high-temperature stress [38/ $28{ }^{\circ} \mathrm{C}$ (day/night)]. High-temperature stress reduced the contents of pyruvate and succinate and inhibited plant growth. The application of exogenous Spd alleviated the inhibition of plant growth induced by high temperature, and also led to an increase in pyruvate, citrate, and succinate levels. High temperature markedly increased the $\mathrm{NH}_{4}{ }^{+}-\mathrm{N}$ content and reduced the activities of nitrate reductase (NR), glutamine synthetase (GS), and glutamate dehydrogenase (GDH). Spd significantly alleviated the negative effects on $\mathrm{NH}_{4}{ }^{+}-\mathrm{N}$ assimilation induced by high-temperature stress. Moreover, Spd significantly increased the activities of NR and GDH in the high-temperature-stressed tomato leaves. In contrast, Spd application to high-temperature-stressed plant leaves counteracted high-temperature-induced mRNA expression changes in $\mathrm{N}$ metabolism. Spd significantly upregulated the transcriptional levels of NR, nitrite reductase, GS, GDH, and glutamate synthase (GOGAT). In addition, exogenous Spd significantly increased endogenous polyamines. These results suggest that Spd could improve carbohydrate and $\mathbf{N}$ status through regulating the gene expression and activity of key enzymes for $\mathbf{N}$ metabolism, thus confers the tolerance to high temperature on tomato seedlings.
\end{abstract}

High temperature is one of the major abiotic factors limiting global agricultural productivity. High temperature directly affects plant physiological and biochemical processes and indirectly changes the growth patterns of plants, reducing plant growth by affecting shoot assimilation rates and creating an imbalance in carbon and $\mathrm{N}$ metabolism (Wahid et al., 2007). High temperature modifies the activities of carbon metabolism enzymes and sucrose synthesis by downregulating specific genes in carbohydrate metabolism (Ruan et al., 2010). Several studies have shown that soluble sugars serve as plant protectants under high-temperature stress (Wahid, 2007; Wahid and Close, 2007). When Saccharum officenarum is subjected to high-temperature stress, the plants accumulate soluble sugars, allowing the plants to develop heat resistance (Wahid, 2007). High-temperature stress can also cause changes in the endogenous hormones of plants (abscisic acid and polyamines) and related biosynthesis (Tian et al., 2012).

Polyamines, mainly putrescine, Spd, and spermine (Spm), are cationic compounds that are ubiquitously distributed in living organisms. Polyamines are involved in the basic physiological processes of various parts of plants, such as leaf senescence, fruit development, and plant response to adversity (Pottosin et al., 2014a). An involvement of polyamines in various potentially protective activities (Gill and Tuteja, 2010), such as mediating the DNA-binding activity of transcription factors (Panagiotidis et al., 1995), radical scavenging, and

Received for publication 11 Mar. 2016. Accepted for publication 25 May 2016 This work was supported by the National Natural Science Foundation of China (No. 31401919, No. 31471869, and No. 31272209), the Central Research Institutes of Basic Research Fund (6J0745), and the China Earmarked Fund for Modern Agro-industry Technology Research System (CARS-25-C-03).

${ }^{1}$ Corresponding author. E-mail: srguo@njau.edu.cn. membrane stabilization (Gupta et al., 2013), have been described. It has been shown that foliar spray with Spd effectively improves the antioxidant ability of Cucumis sativus (Tian et al., 2012). In Arabidopsis thaliana, thermospermine plays a crucial role in plant growth and development (Kim et al., 2014). Polyamine degradation by diamine oxidase produces pyrroline and may also generate $\gamma$-aminobutyric acid, followed by ammonia oxidation inducing aminotransferase or succinate, thereby stimulating the tricarboxylic acid (TCA) cycle. Meanwhile, Spd may protect the enzymes involved in glutamate metabolism (Parvin et al., 2014).

Carbon and $\mathrm{N}$ metabolism involve the perception of the intracellular $\mathrm{C} / \mathrm{N}$ balance and are closely related to photosynthesis and respiration. These types of metabolism are closely related to transcriptional regulation and complex coordination of internal plant activities. Plants assimilate inorganic $\mathrm{N}$ need to consume energy for metabolism, and various types of environmental stress leads plants to lack of energy metabolism, this would affect the plants inorganic $\mathrm{N}$ absorption. This, in turn, affects plant physiological metabolism. Zhang et al. (2007) suggest that the application of exogenous Spd could significantly mitigate the influence of salt stress on cucumber $\mathrm{N}$ metabolism. We examined the ability of tomato seedlings to achieve high-temperature tolerance by applying exogenous Spd. The purpose of this study was to analyze the role of exogenous Spd on carbohydrate and $\mathrm{N}$ metabolism of tomato seedlings under high-temperature stress.

\section{Materials and Methods}

Plant materials and treatments. Tests were conducted on the high-temperature-sensitive tomato (cv. Puhong No. 968) in 
Spring 2014 in a greenhouse at Nanjing Agricultural University (Nanjing, China), and the seedlings were sown in nursery substrate (Zhenjiang Peilei Grey Matrix, Zhenjiang, China) in seedling blocks with one seedling per container. During the seedling stage, the average day/night temperatures were held at $22-24 / 16-18{ }^{\circ} \mathrm{C}$, with $60 \%$ to $70 \%$ relative humidity. After full development of the third true leaves, selected seedlings were placed in climate chambers (Jiangnan Instrument, Ningbo, China). The temperature was set to $25 / 15^{\circ} \mathrm{C}$ (day/night), light intensity $500 \mu \mathrm{mol} \cdot \mathrm{m}^{-2} \cdot \mathrm{s}^{-1}$, photoperiod $12 / 12 \mathrm{~h}, 60 \%$ relative humidity, and the seedlings were allowed to adapt for $2 \mathrm{~d}$ before the experiment. The four experimental treatments were as follows: the plants were grown under normal temperature and the leaves were sprayed with deionized water; the plants were grown under normal temperature and the leaves were sprayed with $1 \mathrm{~mm}$ Spd (Xiaoqiong et al., 2013); the plants were grown under high temperature and the leaves were sprayed with deionized water; and the plants were grown under high temperature and the leaves were sprayed with $1 \mathrm{~mm}$ Spd. Tween-20 [0.5\%, v/v (Haijiechem, Zibo, China)] was used as a surfactant. The normal temperature conditions were $25 / 15^{\circ} \mathrm{C}$ (day/night), and high-temperature conditions were $38 / 28{ }^{\circ} \mathrm{C}$ (day/night). Each day, $2 \mathrm{~h}$ before night, the leaves were sprayed with either water or Spd as a mist on all sides of the leaf at a rate that was without liquid drop formation. Tests were conducted on random plants with three independent replicates.

At $14 \mathrm{~d}$ after planting, samples consisting of the fourth leaf from the base of the plant were collected, immediately snap-frozen in liquid $\mathrm{N}$, and stored at $-80{ }^{\circ} \mathrm{C}$ until required for analysis.

DETERMination OF SUgar, SOLUble PROTEIN, AND ORgaNiC ACID. The sugar, soluble protein, organic acid, and pyruvate content in the leaves of the tomato seedlings were extracted and assayed separately according to Buysse and Merckx (1993), Bradford (1976), Na and Zhuna (2011), and a pyruvate kit (Jiancheng, Nanjing, China), respectively.

ASSAYING ENZYME ACTIVITY. The activity of NR (EC 1.6.6.1) and GDH (EC 1.4.1.2) in the leaves of the tomato seedlings was analyzed by extracting and assaying them according to Foyer et al. (1998) and Singh and Srivastava (1983), respectively. Similarly, the GS EC 6.3.1.2) and GOGAT (EC 1.4.1.14) activities in the leaves of the tomato seedlings were analyzed by extracting and assaying them according to Lin and Kao (1996).

Polyamine Analysis. Sharma and Rajam (1995) developed an improved method for quantifying putrescine, Spd and Spm. Using their methods, $0.5 \mathrm{~g}$ plant materials were added to $1.6 \mathrm{~mL}$ of $5 \%$ precooled perchlorate, ground in an ice bath, and homogenized in $4{ }^{\circ} \mathrm{C}$ for $1 \mathrm{~h}$ followed by $30 \mathrm{~min}$ of $12,000 \mathrm{~g}_{\mathrm{n}}$ centrifugation at $4{ }^{\circ} \mathrm{C}$. The precipitant was collected separately for each sample, and the supernatant was used to determine the free and conjugated polyamines content; the precipitant was used to measure the content of bound polyamines, as described by Tian et al. (2012).

TOTAL RNA EXTRACTION AND REAL-TIME QUANTITATIVE REVERSE TRANSCRIPTION-POLYMERASE CHAIN REACTION ANALYSIS. Total RNA was extracted as described in the TRI reagent protocol (Takara Bio, Shanghai, China) using samples from tomato leaves. For all samples, a PrimeScript ${ }^{\mathrm{TM}}$ first strand cDNA synthesis kit (Takara Bio) was used, and the total RNA was converted to cDNA according to the manufacturer's instructions. Primers were designed according to National
Center for Biotechnology Information. Table 1 provides the gene-specific primers used for real-time quantitative polymerase chain reaction (PCR). Real-time quantitative reverse transcription-polymerase chain reaction (qRT-PCR) was performed with a SYBR PrimeScript ${ }^{\mathrm{TM}}$ RT-PCR Kit (Takara Bio) according to the manufacturer's instructions.

STATISTICAL ANALYSIS. All statistical data were analyzed with the SPSS software (version 20; IBM, Armonk, NY), using Duncan's multiple range tests $(P<0.05)$.

\section{Results}

Growth. As shown in Fig. 1, high-temperature-stress treatment for $14 \mathrm{~d}$ significantly reduced fresh weight and dry weight compared with the control. The application of exogenous $1 \mathrm{~mm}$ Spd greatly alleviated the inhibition of plant growth induced by high temperature. Under the control conditions, Spd exerted no significant effects on growth parameters.

Soluble sugar. As shown in Fig. 2, under the control conditions, Spd exerted no significant effects on soluble sugar. High temperature caused a significant increase in the soluble sugar, fructose, and sucrose contents of the tomato seedlings by $12.6 \%, 13.5 \%$, and $12.0 \%$, respectively. Spd significantly decreased the soluble sugar, fructose, and sucrose contents by $10.7 \%, 14.9 \%$, and $12.8 \%$, respectively, compared with hightemperature stress.

Pyruvate and ORganic aCid. Compared with the control, the pyruvate and succinate contents of the tomato leaves significantly decreased by $16.9 \%$ and $36.0 \%$ (Fig. 3), respectively, under high-temperature stress. Exogenous Spd significantly increased the high-temperature-induced pyruvate, succinate, and citrate contents of tomato seedlings. Spd application to the plants under control temperature did not significantly affect the pyruvate or organic acid contents of the leaves of tomato plants (Fig. 3).

Soluble Protein. As shown in Fig. 4, compared with the control, high-temperature stress caused a significant decrease in the soluble protein contents of tomato leaves by 23.6\%. Exogenous Spd alleviated the high-temperaturestress-induced decrease in protein contents. Although under the control conditions, Spd exerted no significant effects on protein contents.

$\mathrm{NO}_{3}{ }^{-}-\mathbf{N}$ AND $\mathrm{NH}_{4}{ }^{+}-\mathbf{N}$. Compared with the control, hightemperature stress significantly reduced the $\mathrm{NO}_{3}{ }^{-} \mathrm{N}$ contents of tomato seedlings leaves (Fig. 5), but markedly increased the $\mathrm{NH}_{4}{ }^{+}-\mathrm{N}$ contents by $44.2 \%$. The application of exogenous $\mathrm{Spd}$ significantly increased the $\mathrm{NO}_{3}{ }^{-} \mathrm{N}$ contents and decreased the $\mathrm{NH}_{4}{ }^{+}-\mathrm{N}$ contents of plants with high temperature. There were no significant differences in the $\mathrm{NO}_{3}{ }^{-}-\mathrm{N}$ or $\mathrm{NH}_{4}{ }^{+}-\mathrm{N}$ contents between the control seedlings and those supplied with Spd.

Enzymes Related to N metabolism. The NR activity of tomato seedling leaves decreased significantly by $34.0 \%$ under high-temperature stress compared with the control (Fig. 6). Exogenous Spd applied to high-temperature stress significantly elevated NR activity by $45.6 \%$, whereas Spd application to the control seedlings did not affect NR activity.

The activity of GS notably decreased under high-temperature stress. The high-temperature effects on GS activity were improved by exogenous Spd, and the GS level maintained higher values. However, under the control conditions, exogenous Spd had no significant effect on the activities of GS. The GOGAT activity had the same trend as GS activity. 
Table 1. Effects of high-temperature stress and/or exogenous application of $1 \mathrm{~mm}$ spermidine on design of primers for real-time quantitative reverse transcription polymerase chain reaction in leaves of tomato seedlings after 14-d treatments.

\begin{tabular}{lll}
\hline Gene name $^{\mathrm{z}}$ & \multicolumn{1}{c}{ Forward primer $5^{\prime} \rightarrow 3^{\prime}$} & \multicolumn{1}{c}{ Reverse primer $5^{\prime} \rightarrow 3^{\prime}$} \\
\hline Actin & TTCCGTTGCCCAGAGGTCCT & TCGCCCTTTGAAATCCACATC \\
$\mathrm{NR}$ & CAGAGATGTATGTGGTGTAT & CCTTGTGTAATGGATTCTTG \\
$\mathrm{NiR} 1$ & CAGATTCGTGGAGTAGTG & CAACTGGATTCCTGACAT \\
$\mathrm{NiR2}$ & GCAATGTGGATGTGACTA & CAGGCATATACGCAAGAT \\
$G S$ & CCATCTTCATCTTCTTCTCT & ATTCTCATCTGCCATTGT \\
$l e G D H$ & AGCAGTGAGTGACATAAC & ACAGTCTTCTACCAGTATTG \\
$G D H$ & TCATTCATCTAACTGGACTG & TCGGCATACTTACAACAG
\end{tabular}

${ }^{\mathrm{z}}$ actin $=$ actin; $G D H=$ glutamate dehydrogenase; $G S=$ glutamine synthetase; $l e G D H=$ glutamate dehydrogenase fragment; $N i R 1=$ nitrite reductase small fragment $1 ; N i R 2=$ nitrite reductase small fragment $2 ; N R=$ nitrate reductase.
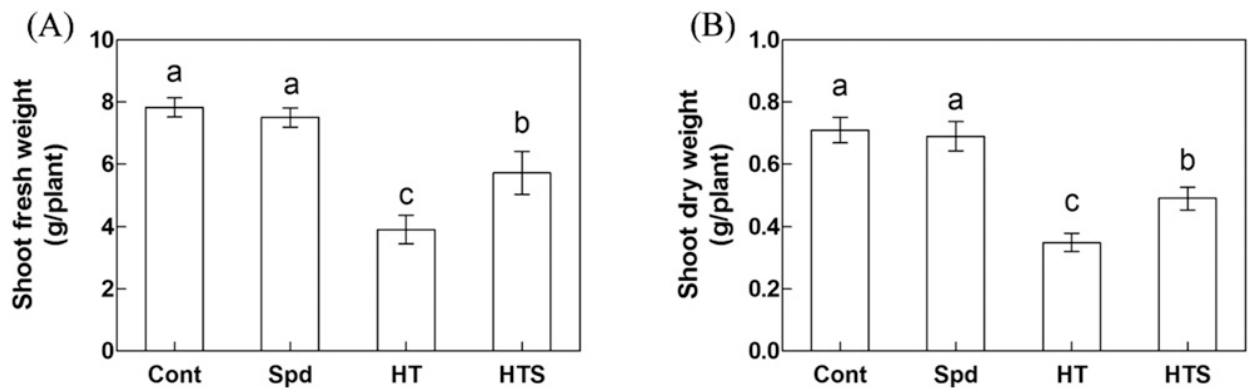

Fig. 1. Effects of high-temperature stress and/or exogenous application of $1 \mathrm{~mm}$ spermidine (Spd) on the (A) fresh weight and (B) dry weight in leaves of tomato seedlings after 14-d treatments. Cont $=$ control plants under $25 / 15^{\circ} \mathrm{C}$ (day/night); HT = plants under $38 / 28^{\circ} \mathrm{C}$; HTS = plants under $38 / 28^{\circ} \mathrm{C}$ with Spd foliar spraying; Spd = control plants under $25 / 15^{\circ} \mathrm{C}$ with $\mathrm{Spd}$ foliar spraying. Values shown are means of three independent experiments. Different letters indicate significant differences via Duncan's multiple range tests at $P<0.05$.
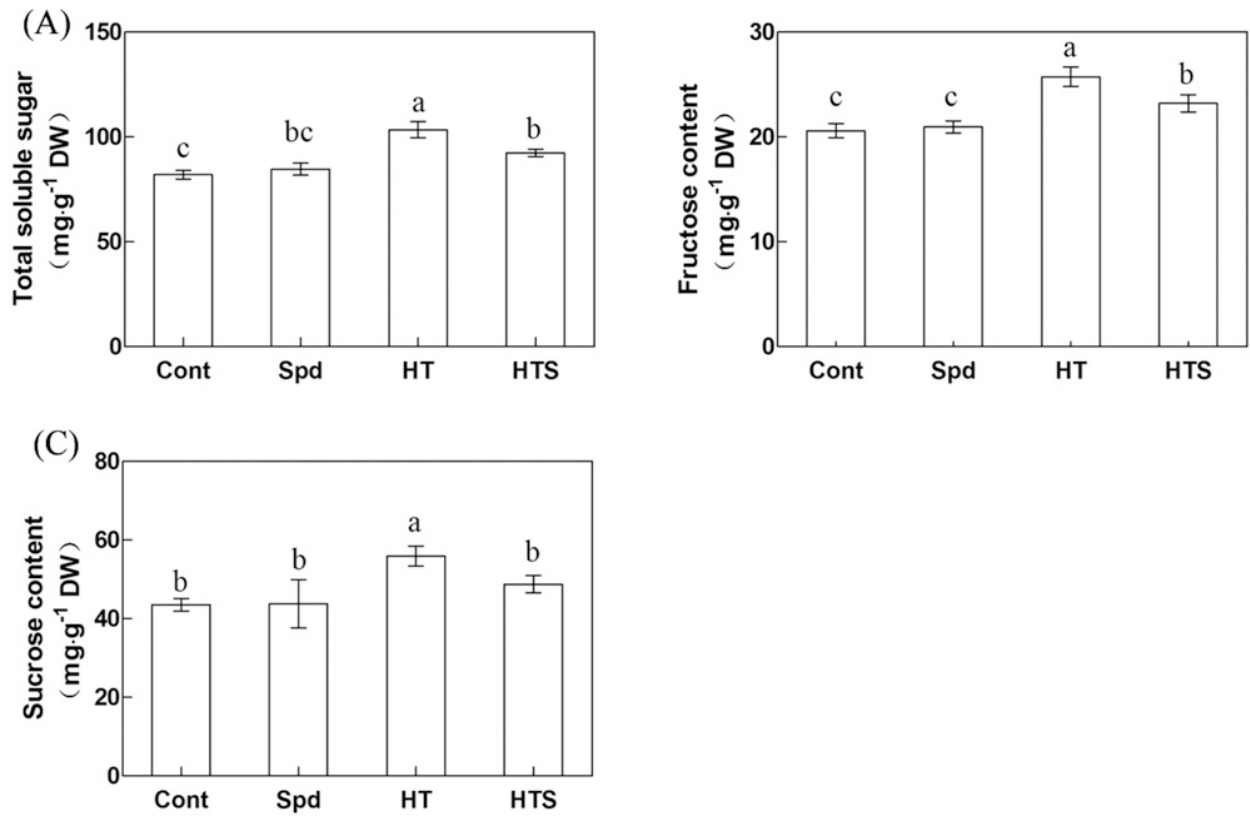

Fig. 2. Effects of high-temperature stress and/or exogenous application of $1 \mathrm{~mm}$ spermidine (Spd) on (A) total sugar, (B) fructose, and (C) sucrose contents in leaves of tomato seedlings after 14-d treatments: Cont $=$ control plants under $25 / 15^{\circ} \mathrm{C}$ (day/night); $\mathrm{HT}=$ plants under $38 / 28^{\circ} \mathrm{C}$; $\mathrm{HTS}=$ plants under $38 / 28^{\circ} \mathrm{C}$ with $\mathrm{Spd}$ foliar spraying; $\mathrm{Spd}=$ control plants under $25 / 15^{\circ} \mathrm{C}$ with Spd foliar spraying. Values shown are means of three independent experiments. Different letters indicate significant differences via Duncan's multiple range tests at $P<0.05$.
As shown in Fig. 6, compared with the control, high temperature caused a decrease in GDH activity. The application of exogenous Spd significantly increased the value of GDH activity under high temperatures. Meanwhile, there were no significant differences between the GDH activities of the control plants and those applied with Spd.

THE GENE EXPRESSION PATTERNS OF IMPORTANT ENZYMES RELATED TO N metabolism. We analyzed six transcript expression profiles, which encoded the key enzymes of $\mathrm{N}$ metabolism using real-time qRT-PCR. As shown in Fig. 7, the transcriptional levels of those genes significantly varied with the addition of high temperature and Spd. Under high-temperature stress, the tomato seedlings had increased transcriptional levels of NR, nitrite reductase, GS, and glutamate dehydrogenase and decreased transcriptional levels of nitrite reductase and GDH. Exogenous Spd regulated the high-temperaturestress-mediated accumulation of transcripts.

Polyamines. High temperature caused a significant increase in free polyamines (Fig. 8). Exogenous Spd increased the high-temperaturestress-induced free polyamines and exerted a significantly increased effect on free polyamines. Under the control conditions, Spd significantly increased endogenous free polyamines.

As shown in Fig. 8, compared with the control, high temperature caused a significant increase in conjugated Spd. Exogenous Spd significantly increased conjugated putrescine and Spd, but there were no significant differences in conjugated Spm under high temperature. Spd application to the control plants did not affect these conjugated polyamines. The bound Spd and Spm showed no significant change in high-temperaturestressed seedlings; compared with the control, high temperature significantly decreased the bound putrescine. Exogenous Spd had no significant differences in bound putrescine and Spm under high temperature, but increased Spd significantly. 
(A)

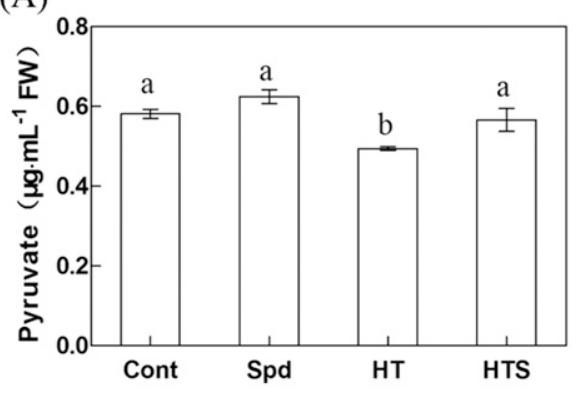

(C)

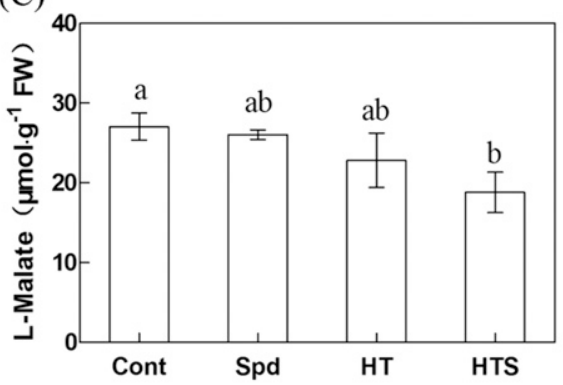

(B)

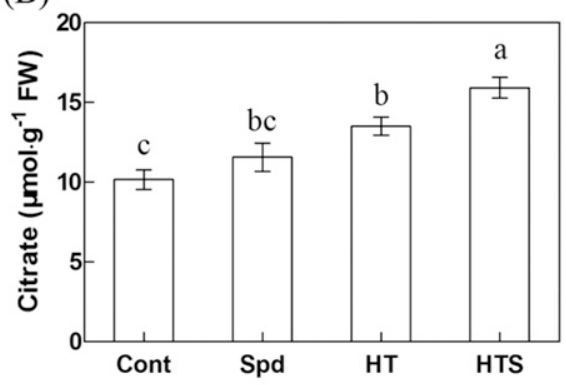

(D)

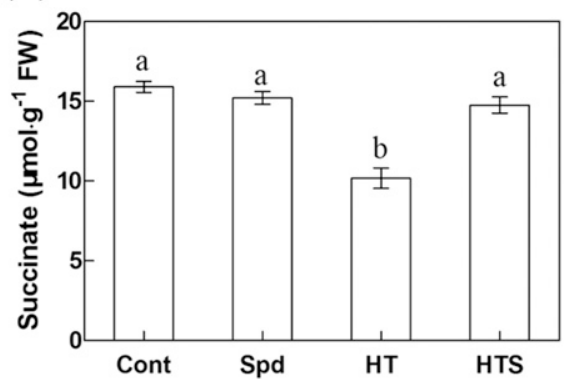

reporting the carbohydrate status within the cell (Ruan et al., 2010). Under high-temperature stress, the phloem callose layer thickens, blocking the mesh, and the phloem transport resistance increases, so that the outward transport of the photosynthetic product cannot be timely (Wolf, 1993). We observed that high-temperature stress increased sucrose. The accumulation of sucrose limited the maximal rates of photosynthesis (Yuan et al., 2014) and restricted carbon fixation in the chloroplast. When sucrose export was blocked, excess carbohydrates in photosynthetic cells could downregulate photosynthetic gene expression (Zhao et al., 2015). The application of Spd decreased sucrose (Fig. 2). The leaves could be the polyamine pool, and spraying Spd induced polyamine transport (Imene et al., 2010). The transported polyamines may be Spd (Moschou et al., 2009). So we speculated, the transportation of the Spd may deter callose layer thickening, promoting the transport of sucrose outward. Poly(B) citrate, (C) malate, and (D) succinate contents in leaves of tomato seedlings after 14-d treatments: Cont = control plants under $25 / 15^{\circ} \mathrm{C}$ (day/night); HT = plants under $38 / 28^{\circ} \mathrm{C}$; HTS = plants under $38 / 28{ }^{\circ} \mathrm{C}$ with Spd foliar spraying; $\mathrm{Spd}=$ control plants under $25 / 15^{\circ} \mathrm{C}$ with Spd foliar spraying. Values shown are means of three independent experiments. Different letters indicate significant differences via Duncan's multiple range tests at $P<0.05$.

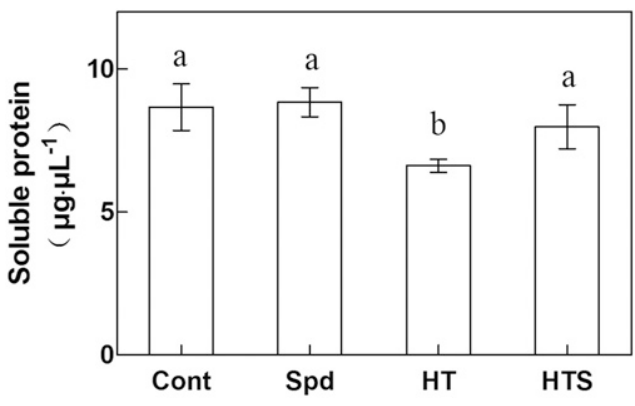

Fig. 4. Effects of high-temperature stress and/or exogenous application of $1 \mathrm{~mm}$ spermidine (Spd) on soluble protein contents in leaves of tomato seedlings after 14-d treatments: Cont $=$ control plants under $25 / 15^{\circ} \mathrm{C}$ (day/night); $\mathrm{HT}=$ plants under $38 / 28^{\circ} \mathrm{C}$; HTS $=$ plants under $38 / 28^{\circ} \mathrm{C}$ with Spd foliar spraying; $\mathrm{Spd}=$ control plants under $25 / 15^{\circ} \mathrm{C}$ with $\mathrm{Spd}$ foliar spraying. Values shown are means of three independent experiments. Different letters indicate significant differences via Duncan's multiple range tests at $P<0.05$.

\section{Discussion}

High-temperature stress induces changes in respiration and thus leads to a shortened life cycle and diminished plant productivity (Nahar et al., 2016). Growth analysis is widely used as a tool for characterizing plant growth (Glaubitz et al., 2015). Our experiments showed that exogenous Spd significantly alleviated the growth inhibition by high-temperature stress and increased biomass accumulation. It is probable that Spd alleviated the inhibition of plant growth via regulating the metabolites involved in carbohydrate and $\mathrm{N}$ metabolism.

Sucrose not only serves as the major endproduct of photosynthetic carbon fixation but also acts as a signaling molecule amines positively charged at physiological $\mathrm{pH}$ could affect physiological systems by binding to anionic sites, such as those associated with nucleic acids, membrane phospholipids, and DNA replication, which could provide an appropriate environment for cell metabolism, accelerating the sucrose assimilation pathway.

In our study, high temperature decreased the levels of pyruvate and TCA-derived organic acids (Fig. 3), suggesting that the glycolysis and TCA cycle were hindered, which could lead to plant carbon starvation, eventually influencing other mechanisms. Exogenous Spd increased pyruvate, which could be the result of increased glycolysis metabolic pathways. A recent study reported that exogenous Spd could enhance photosynthesis by regulating the gene expression and activities of key enzymes for $\mathrm{CO}_{2}$ fixation (Shu et al., 2014). More photosynthetic products could therefore enter glycolysis metabolism. Exogenous Spd increased succinate under high temperatures (Fig. 3), presumably attempting to maintain a supply for the mitochondrial electron transport chain. This compensatory response might shift the cellular pools of carbon. Correlation analyses indicated that the correlations of polyamine levels with the organic acid metabolic network were positively correlated in high night temperature sensitivity (Glaubitz et al., 2015). In the transgenic tomato fruit, large amounts of Spd revealed high organic acid metabolism (Handa and Mattoo, 2010).

Regulating the balance between carbon and $\mathrm{N}$ metabolism is crucial. Our study showed that high temperature decreased soluble protein. Direct injuries due to high temperatures include protein denaturation and aggregation (Askim et al., 2014), inhibition of protein synthesis, protein degradation, and loss of membrane integrity (Wahid et al., 2007). Protein degradation 
(A)

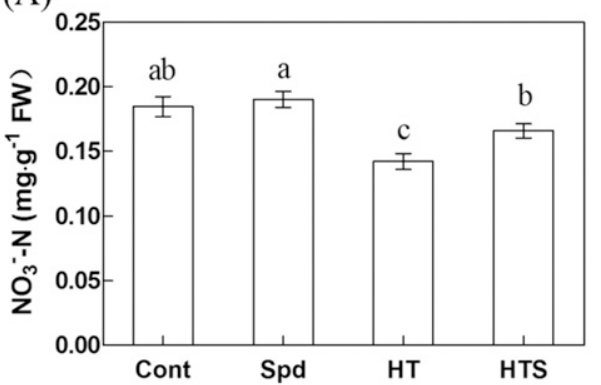

(B)

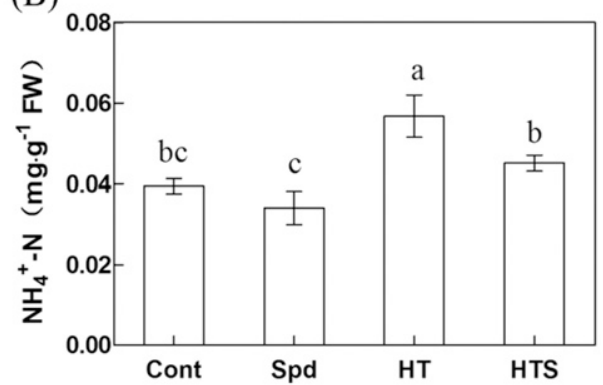

Fig. 5. Effects of high-temperature stress and/or exogenous application of $1 \mathrm{~mm}$ spermidine ( $\mathrm{Spd})$ on $(\mathbf{A}) \mathrm{NO}_{3}{ }^{-}-\mathrm{N}^{2}$ and (B) $\mathrm{NH}_{4}{ }^{+}-\mathrm{N}$ contents in leaves of tomato seedlings after 14-d treatments: Cont $=$ control plants under $25 / 15^{\circ} \mathrm{C}$ (day/night) $\mathrm{HT}=$ plants under $38 / 28{ }^{\circ} \mathrm{C}$; HTS = plants under $38 / 28{ }^{\circ} \mathrm{C}$ with Spd foliar spraying; Spd = control plants under $25 / 15{ }^{\circ} \mathrm{C}$ with $\mathrm{Spd}$ foliar spraying. Values shown are means of three independent experiments. Different letters indicate significant differences via Duncan's multiple range tests at $P<0.05$.
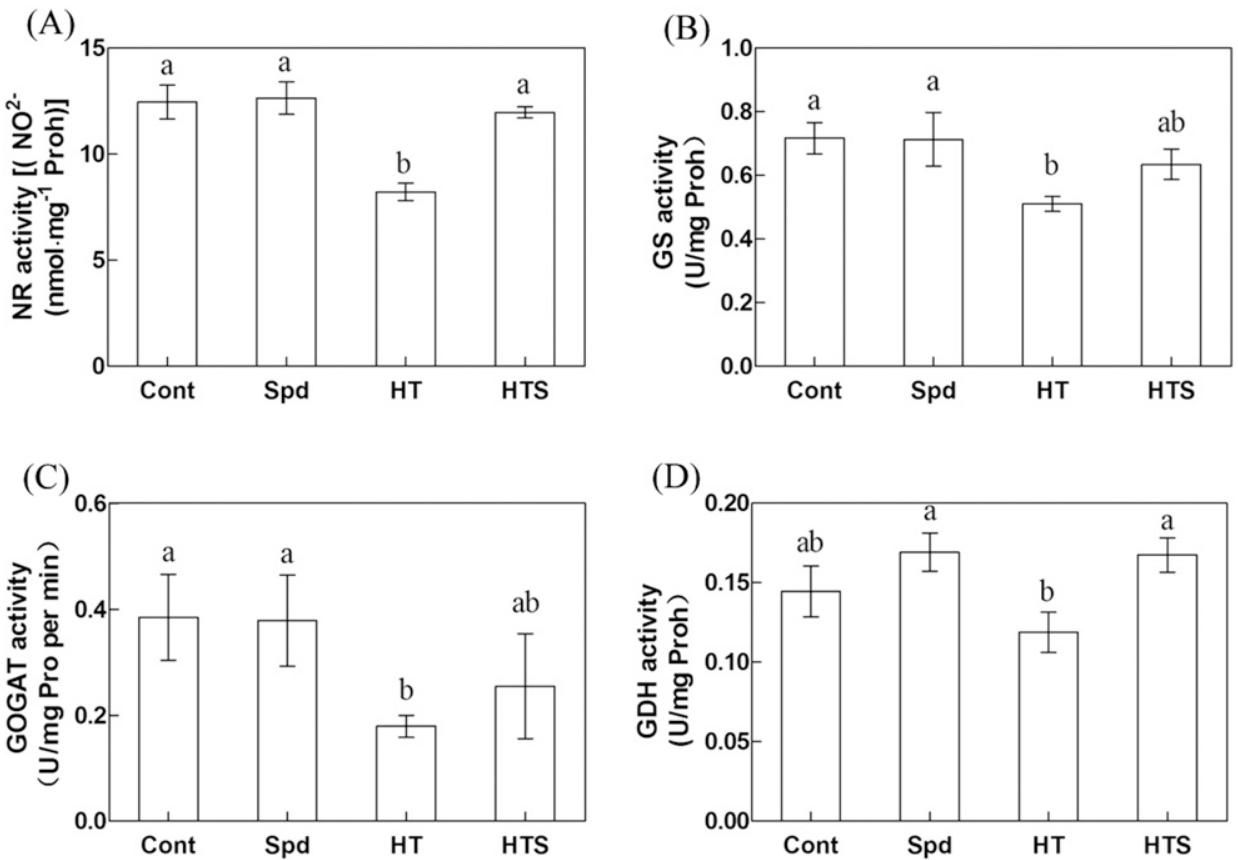

Fig. 6. Effects of high-temperature stress and/or exogenous application of $1 \mathrm{~mm}$ spermidine (Spd) on the activity of nitrogen metabolism enzymes (A) nitrate reductase (NR), (B) glutamine synthetase (GS), (C) glutamate synthase(GOGAT), and (D) glutamate dehydrogenase (GDH) in leaves of tomato seedlings after 14-d treatments: Cont $=$ control plants under $25 / 15^{\circ} \mathrm{C}$ (day/night); $\mathrm{HT}=$ plants under $38 / 28^{\circ} \mathrm{C}$; HTS $=$ plants under $38 / 28^{\circ} \mathrm{C}$ with Spd foliar spraying; $\mathrm{Spd}=$ control plants under $25 / 15^{\circ} \mathrm{C}$ with $\mathrm{Spd}$ foliar spraying. Values shown are means of three independent experiments. Different letters indicate significant differences via Duncan's multiple range tests at $P<0.05$.

accounts for a significant part of energy consumption, which accelerated carbon starvation, so that seedlings cannot provide an alternative source of carbon for respiration (Ishihara et al., 2015). Polyamines are aliphatic $\mathrm{N}$ compounds positively charged at physiological $\mathrm{pH}$. This property allows polyamines to interact with negatively charged macromolecules as proteins (Galston and Sawhney, 1990). Polyamine metabolism contributes to the $\mathrm{N}$ flow in plants, so we proposed that Spd is a form of organic N, which then signals changes in various amino acids. It has been shown Spd and Spm are positive regulators of cellular amino acid metabolism (Mattoo et al., 2010). Thus, polyamines induce numerous changes in the expression of a large number of genes, which have consequences on cellular metabolism and target genes involved in amino acid biosynthesis (Srivastava et al., 2007) and protein biosynthesis.

High-temperature stress resulted in decreased energy production and disrupted metabolic processes that required energy-intensive chemical reactions. The absorption of $\mathrm{NO}_{3}{ }^{-}-\mathrm{N}$ is an active process that will consume a large proportion of the energy from photosynthesis. High temperature resulted in reduced levels of the total $\mathrm{NO}_{3}{ }^{-}-\mathrm{N}$ and the activity of NR. Exogenous Spd increased the NR activity and thus enhanced the capacity of nitrate reduction. Furthermore, NR is sensitive to $\mathrm{H}_{2} \mathrm{O}_{2}$ (Yuan et al., 2014). The accumulation of $\mathrm{H}_{2} \mathrm{O}_{2}$ induced by high temperature inhibited NR activity. Spd treatment in tomato seedlings subjected to high temperature could reduce the content of $\mathrm{H}_{2} \mathrm{O}_{2}$, releasing the inhibition to NR. Ammonium ions, which are the final forms of inorganic $\mathrm{N}$ before the organic $\mathrm{N}$ compounds, are continuously generated during various metabolic processes. The assimilation of ammonium into amino acids requires the concerted role of GS/ GOGAT, which is a key pathway in $\mathrm{N}$ assimilation. An amount of ammonium is needed for the enzymatic action of GS activity in the roots or shoots (Setién et al., 2013). High temperature significantly reduced GS activity (Fig. 6), resulting in an excess of ammonium, which might result in ammonium toxicity. The accumulation of $\mathrm{NH}_{4}{ }^{+}-\mathrm{N}$ could inhibit photosynthesis and plant growth and alter the $\mathrm{N}$ assimilation pathway in the leaves. Exogenous Spd did not significantly affect the GS or GOGAT activities, but the GDH activity was significantly increased, which indicated that ammonia assimilation had shifted from the normal GS/GOGAT pathway to the GDH pathway (Yuan et al., 2014). Spd has the characteristics of a cationic polymer in free and combined forms with proteins and nucleic acid, so it could protect these enzymatic activities. In addition, the $\mathrm{N}$ flow toward polyamines may serve as a strategy of cells to (re)store $\mathrm{N}$, or alternatively polyamines could act as sinks for excess $\mathrm{NH}_{4}{ }^{+} \mathrm{N}$ (Moschou et al., 2012). Plants with higher GDH activities were more tolerant to the amount of ammonium. Several studies have indicated that GDH may catalyze the deamination of glutamate into ammonium and $\alpha$-ketoglutarate (Setién et al., 2013). However, for tomato (Horchani et al., 2010), when there is excess ammonium and GS activity is inhibited, GDH might be involved in ammonium 
(A)

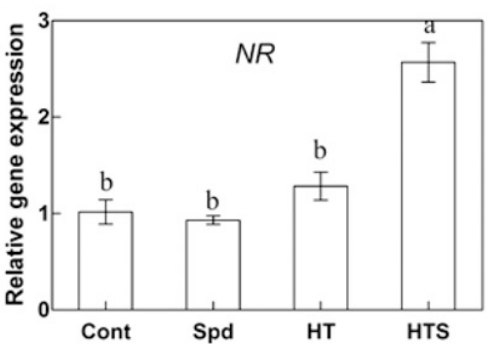

(D)

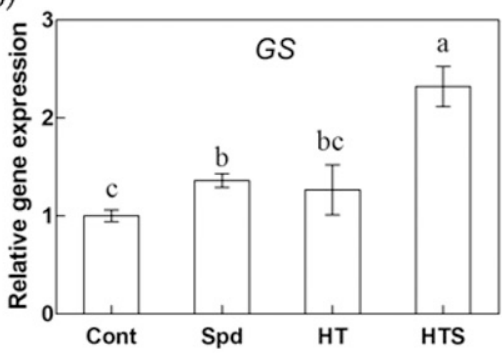

(B)

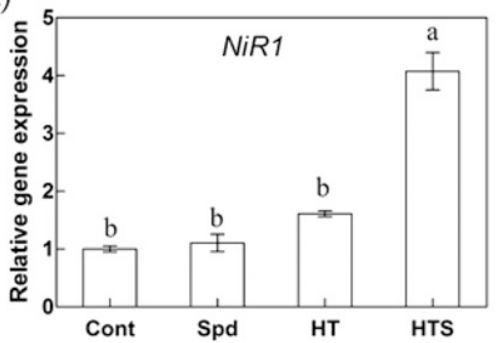

(E)

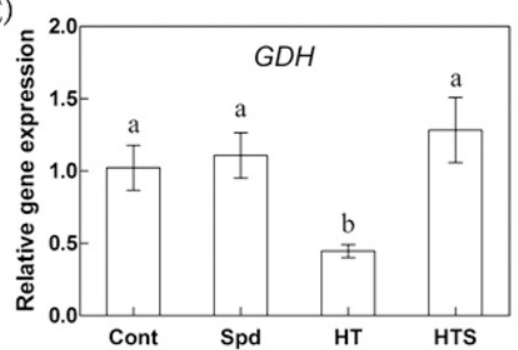

(C)

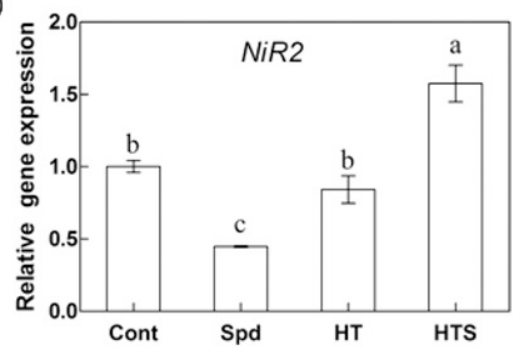

(F)

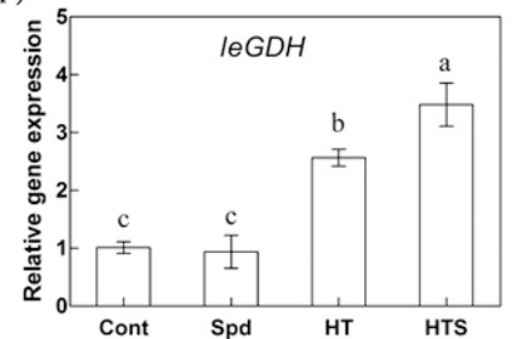

Fig. 7. Effects of high-temperature stress and/or exogenous application of $1 \mathrm{~mm}$ spermidine (Spd) on expression of (A) nitrate reductase (NR), (B) nitrite reductase small fragment $1(N i R 1),(\mathbf{C})$ nitrite reductase small fragment $2(N i R 2),(\mathbf{D})$ glutamine synthetase $(G S),(\mathbf{E})$ glutamate dehydrogenase $(G D H)$, and $(\mathbf{F})$ glutamate dehydrogenase fragment $(l e G D H)$ in leaves of tomato seedlings after $14-\mathrm{d}$ treatments: Cont $=$ control plants under $25 / 15^{\circ} \mathrm{C}($ day $/$ night $) ; \mathrm{HT}=$ plants under $38 / 28^{\circ} \mathrm{C}$; HTS = plants under $38 / 28^{\circ} \mathrm{C}$ with Spd foliar spraying; Spd $=$ control plants under $25 / 15^{\circ} \mathrm{C}$ with Spd foliar spraying. Values shown are means of three independent experiments. Different letters indicate significant differences via Duncan's multiple range tests at $P<0.05$.

(A)
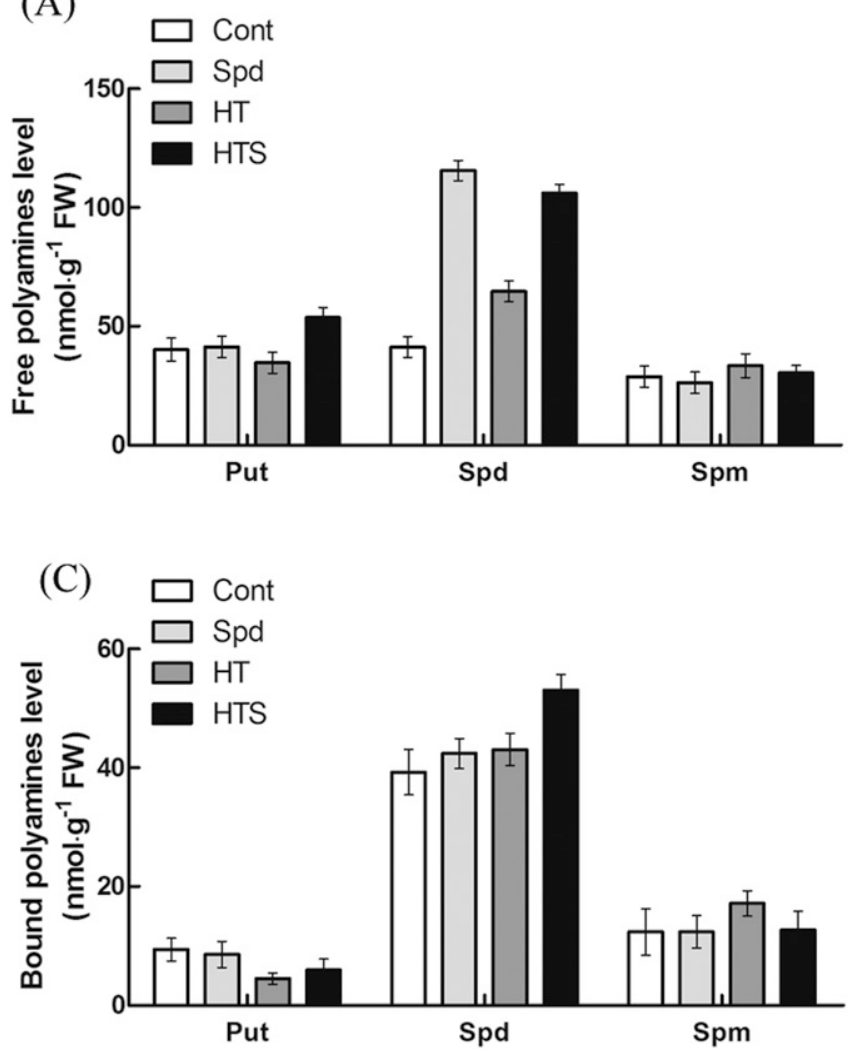

(B)

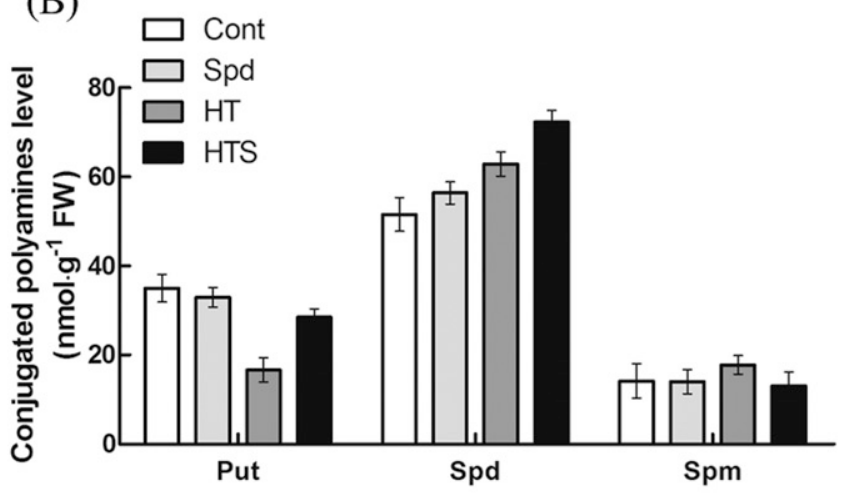

Fig. 8. Effects of high-temperature stress and/or exogenous application of $1 \mathrm{~mm}$ spermidine (Spd) on (A) free polyamine [putrescine (Put), spermine (Spm)], (B) conjugated polyamine, and $(\mathbf{C})$ bound polyamine contents in leaves of tomato seedlings after $14-\mathrm{d}$ treatments: Cont $=$ control plants under $25 / 15^{\circ} \mathrm{C}(\mathrm{day} / \mathrm{night})$; $\mathrm{HT}=$ plants under $38 / 28^{\circ} \mathrm{C}$; HTS = plants under $38 / 28^{\circ} \mathrm{C}$ with Spd foliar spraying; Spd = control plants under $25 / 15^{\circ} \mathrm{C}$ with Spd foliar spraying. Values shown are means of three independent experiments. Different letters indicate significant differences via Duncan's multiple range tests at $P<0.05$.

assimilation. In our results, exogenous Spd significantly reduced the accumulation of $\mathrm{NH}_{4}{ }^{+}-\mathrm{N}$ through increasing the key enzyme activities involved in the ammonia assimilation.
In general, plant species with strong tolerance to stresses are endowed with a capacity to enhance polyamines biosynthesis in response to environmental stresses (Gupta et al., 2013). Under 
high temperatures, endogenous polyamines increase significantly. Exogenous Spd application modulated the endogenous polyamines contents under high temperatures. Of the three major polyamines, Spd had the highest levels in tomato seedlings. It is possible that glutamate might serve as a substrate in polyamines biosynthesis and could also be involved in the pronounced increase in Spd levels (Milená et al., 2013). Polyamines can act as an effective scavenger of free radicals, activating the antioxidant enzyme activity (Pottosin et al., 2014b). Furthermore, Spd-treated rice seedlings exposed to high temperatures showed significantly increased ascorbate and glutathione contents and high ratios of ascorbate/dehydroascorbate, which can account for the higher antioxidant capacity (Mostofa et al., 2013). It has been shown that exogenous Spd regulates endogenous polyamines (Mostofa et al., 2013), polyamine biosynthesis genes, hormone pathways, and oxidation reduction genes to alleviate hightemperature injury (Lin et al., 2012), which suggests that Spd might be the most important type of polyamines for tomato seedlings to obtain heat adaptability.

\section{Conclusions}

Under high-temperature stress, the carbon and $\mathrm{N}$ metabolism of tomato seedlings experienced a range of disorders. Exogenous Spd could accelerate sugar consumption and transportation, thus promoting the TCA cycle, allowing the plant to produce other metabolic precursor substances. Exogenous Spd could effectively restrain the effects of ammonium in tomato leaves while promoting $\mathrm{N}$ metabolism related to enzyme activities and gene expression. The foliar spraying of Spd thus increased the heat tolerance of tomato seedlings by adjusting the contents of three polyamines and inducing a strong carbon and $\mathrm{N}$ metabolism system to alleviate the stress induced by high-temperature stress.

\section{Literature Cited}

Askim, H.S., R. Ozgur, B. Uzilday, and I. Turkan. 2014. Reactive oxygen species scavenging capacities of cotton (Gossypium hirsutum) cultivars under combined drought and heat induced oxidative stress. Environ. Expt. Bot. 99:141-149.

Bradford, M.M. 1976. A rapid and sensitive method for the quantitation of microgram quantities of protein utilizing the principle of protein-dye binding. Anal. Biochem. 72:248-254.

Buysse, J. and R. Merckx. 1993. An improved colorimetric method to quantify sugar content of plant tissue. J. Expt. Bot. 44:16271629.

Foyer, C.H., M.H. Valadier, A. Migge, and T.W. Becker. 1998. Drought-induced effects on nitrate reductase activity and mRNA and on the coordination of nitrogen and carbon metabolism in maize leaves. Plant Physiol. 117:283-292.

Galston, A.W. and R.K. Sawhney. 1990. Polyamines in plant physiology. Plant Physiol. 94:406-410.

Gill, S.S. and N. Tuteja. 2010. Polyamines and abiotic stress tolerance in plants. Plant Signal. Behav. 5:26-33.

Glaubitz, U., A. Erban, J. Kopka, D.K. Hincha, and E. Zuther. 2015. High night temperature strongly impacts TCA cycle, amino acid and polyamine biosynthetic pathways in rice in a sensitivity-dependent manner. J. Expt. Bot. 66:6385-6397.

Gupta, K., A. Dey, and B. Gupta. 2013. Plant polyamines in abiotic stress responses. Acta Physiol. Plant. 35:2015-2036.

Handa, A.K. and A.K. Mattoo. 2010. Differential and functional interactions emphasize the multiple roles of polyamines in plants. Plant Physiol. Biochem. 48:540-546.
Horchani, F., R. Hajri, and S. Aschi-Smiti. 2010. Effect of ammonium or nitrate nutrition on photosynthesis, growth, and nitrogen assimilation in tomato plants. J. Plant Nutr. Soil 173:610-617.

Imene, T., P.N. Moschou, K.A. Paschalidis, B. Badra, S.F. Asma, W.G. Abdel, M. Ahmed, and K.A. Roubelakis-Angelakis. 2010. Abscisic acid signals reorientation of polyamine metabolism to orchestrate stress responses via the polyamine exodus pathway in grapevine. J. Plant Physiol. 167:519-525.

Ishihara, H., T. Obata, R. Sulpice, R.F. Alisdair, and M. Stitt. 2015. Quantifying protein synthesis and degradation in Arabidopsis by dynamic ${ }^{13} \mathrm{CO}_{2}$ labeling and analysis of enrichment in individual amino acids in their free pools and in protein. Plant Physiol. 99:209-215.

Kim, D.W., K. Watanabe, C. Murayama, S. Izawa, M. Niitsu, A.J. Michael, T. Berberich, and T. Kusano. 2014. Polyamine oxidase5 regulates Arabidopsis growth through thermospermine oxidase activity. Plant Physiol. 165:1575-1590.

Lin, C.C. and C.H. Kao. 1996. Disturbed ammonium assimilation is associated with growth inhibition of roots in rice seedlings caused by $\mathrm{NaCl}$. Plant Growth Regulat. 18:233-238.

Lin, C., R.R. Sun, F.Y. Wang, P. Zhen, F.L. Kong, W.U. Jian, J.S. Cao, and L.U. Gang. 2012. Spermidine affects the transcriptome responses to high temperature stress in ripening tomato fruit. J. Zhejiang Univ. Sci. 13:283-297.

Mattoo, A.K., S.C. Minocha, M. Rakesh, and A.K. Handa. 2010. Polyamines and cellular metabolism in plants: Transgenic approaches reveal different responses to diamine putrescine versus higher polyamines spermidine and spermine. Amino Acids 38:405-413.

Milená, C., L. Gemperlová, O. Martincová, and R. Vanková. 2013. Effect of drought and combined drought and heat stress on polyamine metabolism in proline-over-producing tobacco plants. Plant Physiol. Biochem. 73:7-15.

Moschou, P., P. Sarris, N. Skandalis, A. Andriopoulou, K. Paschalidis, N. Panopoulos, and K. Roubelakis-Angelakis. 2009. Engineered polyamine catabolism preinduces tolerance of tobacco to bacteria and oomycetes. Plant Physiol. 149:1970-1981.

Moschou, P.N., J. Wu, A. Cona, P. Tavladoraki, R. Angelini, and K.A. Roubelakis-Angelakis. 2012. The polyamines and their catabolic products are significant players in the turnover of nitrogenous molecules in plants. J. Expt. Bot. 63:5003-5015.

Mostofa, M.G., N. Yoshida, and M. Fujita. 2013. Spermidine pretreatment enhances heat tolerance in rice seedlings through modulating antioxidative and glyoxalase systems. Plant Growth Regulat. $73: 31-44$.

Na, L. and W. Zhuna. 2011. Tropical fruit pulp 4 kinds of organic acids by reversed phase high performance liquid chromatography (HPLC) method (in China). China Fruit Tree 4:44-47.

Nahar, K., M. Hasanuzzaman, M.M. Alam, A. Rahman, J.A. Mahmud, T. Suzuki, and M. Fujita. 2016. Insights into spermine-induced combined high temperature and drought tolerance in mung bean: Osmoregulation and roles of antioxidant and glyoxalase system. Protoplasma 1-16.

Panagiotidis, C.A., S. Artandi, K. Calame, and S.J. Silverstein. 1995. Polyamines alter sequence-specific DNA-protein interactions. Nucleic Acids Res. 23:1800-1809.

Parvin, S., O.R. Lee, G. Sathiyaraj, A. Khorolragchaa, Y.J. Kim, and D.C. Yang. 2014. Spermidine alleviates the growth of saline-stressed ginseng seedlings through antioxidative defense system. Gene 537:70-78.

Pottosin, I., A.M. Velarde-Buendía, J. Bose, A.T. Fuglsang, and S. Shabala. 2014a. Polyamines cause plasma membrane depolarization, activate $\mathrm{Ca}^{2+}$, and modulate $\mathrm{H}^{+}$-ATPase pump activity in pea roots. J. Expt. Bot. 65:2463-2472.

Pottosin, I., A.M. Velarde-Buendía, J. Bose, I. Zepeda-Jazo, S. Shabala, and O. Dobrovinskaya. 2014b. Cross-talk between reactive oxygen species and polyamines in regulation of ion transport across the plasma membrane: Implications for plant adaptive responses. J. Expt. Bot. 65:1271-1283. 
Ruan, Y.L., Y. Jin, Y.J. Yang, G.J. Li, and J.S. Boyer. 2010. Sugar input, metabolism, and signaling mediated by invertase: Roles in development, yield potential, and response to drought and heat. Mol. Plant 3:942-955.

Setién, I., T. Fuertes-Mendizabal, A. González, P.M. Aparicio-Tejo, C. González-Murua, M.B. González-Moro, and J.M. Estavillo. 2013. High irradiance improves ammonium tolerance in wheat plants by increasing N assimilation. J. Plant Physiol. 170:758-771.

Sharma, P. and M. Rajam. 1995. Spatial and temporal changes in endogenous polyamine levels associated with somatic embryogenesis from different hypocotyl of eggplant (Solanum melongena L.). J. Plant Physiol. 146:658-664.

Shu, S., L.F. Chen, W. Lu, J. Sun, S.R. Guo, Y.H. Yuan, and J. Li. 2014. Effects of exogenous spermidine on photosynthetic capacity and expression of Calvin cycle genes in salt-stressed cucumber seedlings. J. Plant Res. 127:763-773.

Singh, R.P. and H.S. Srivastava. 1983. Regulation of glutamate dehydrogenase activity by amino acids in maize seedlings. Physiol. Plant. 57:549-554.

Srivastava, A., C.S. Ho, T. Fatima, T. Datsenka, A.K. Handa, and A.K. Mattoo. 2007. Polyamines as anabolic growth regulators revealed by transcriptome analysis and metabolite profiles of tomato fruits engineered to accumulate spermidine and spermine. Plant Biotechnol. 24:57-70.

Tian, J., L.P. Wang, Y.J. Yang, J. Sun, and S.R. Guo. 2012. Exogenous spermidine alleviates the oxidative damage in cucumber seedlings subjected to high temperatures. J. Amer. Soc. Hort. Sci. 137:11-19.
Wahid, A. 2007. Physiological implications of metabolite biosynthesis for net assimilation and heat-stress tolerance of sugarcane (Saccharum officinarum) sprouts. J. Plant Res. 120:219-228.

Wahid, A. and T. Close. 2007. Expression of dehydrins under heat stress and their relationship with water relations of sugarcane leaves. Biol. Plant. 51:104-109.

Wahid, A., S. Gelani, M. Ashraf, and M.R. Foolad. 2007. Heat tolerance in plants: An overview. Environ. Expt. Bot. 61:199223.

Wolf, S. 1993. Effect of leaf age on photosynthesis, carbon transport and carbon allocation in potato plants. Potato Res. 36:253-262.

Xiaoqiong, S., W. Meiyue, S. Sheng, S. Jin, and G. Shirong. 2013. Effects of exogenous spermidine on the fast chlorophyll fluorescence induction dynamics in tomato seedlings under high temperature stress (in China). Chinese J. Hort. 40:2409-2418.

Yuan, L., S. Zhu, S. Li, S. Shu, J. Sun, and S.R. Guo. 2014. 24Epibrassinolide regulates carbohydrate metabolism and increases polyamine content in cucumber exposed to $\mathrm{Ca}\left(\mathrm{NO}_{3}\right)_{2}$ stress. Acta Physiol. Plant. 36:2845-2852.

Zhang, H., H. Rong, and D. Pilbeam. 2007. Signalling mechanisms underlying the morphological responses of the root system to nitrogen in Arabidopsis thaliana. J. Expt. Bot. 58:23-38.

Zhao, H., T. Su, L. Huo, H. Wei, Y. Jiang, L. Xu, and F. Ma. 2015. Unveiling the mechanism of melatonin impacts on maize seedling growth: Sugar metabolism as a case. J. Pineal Res. 59:255266. 